\title{
Whose Standards? (B) Reaching The Assessment Puzzle
}

John M. Polimeni, Albany College of Pharmacy and Health Sciences, USA

Raluca I. Iorgulescu, Siena College, USA

\begin{abstract}
Love it or hate it, assessment has become the new reality on college and university campuses. Although measuring student achievement of course outcomes is not an easy task, assessment does not need to be a complex or painful experience. This paper describes the methods used to assess student achievement of the stated course outcomes in introductory level economics courses at two different colleges, the Albany College of Pharmacy and Health Sciences (ACPHS) and Siena College, during the 2007 academic year. Specifically, we outline the course assessment activities that are used. We examine whether there are differences in the attainment of the course objectives of the students at the two very different institutions. Finally, we argue that an assessment exam designed using the course objectives is a better assessment tool than a standardized test.
\end{abstract}

Keywords: Active Learning, Assessment of Higher Education, Economics Education

\section{INTRODUCTION}

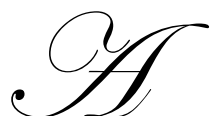

ccreditation agencies, pressured by the U.S. Department of Education, are creating a whirlwind of assessment activities on colleges and universities. For example, the Association of American Colleges and Universities (2002) has strongly suggested a reorganization of undergraduate education by focusing on the achievement of course outcomes to ensure that students receive an education that has lasting value. This development materialized in the $1980 \mathrm{~s}$, but, in large part, did not come into the forefront until the mid to late 1990s. Demonstrating accountability on the part of colleges and universities became even more important in the last few years as Secretary of Education Margaret Spelling convened the Commission on the Future of Higher Education. The Commission stated that "accreditation agencies should make performance outcomes, including completion rates and student learning, the core of their assessment as a priority over inputs or processes" (U.S. Department of Education, p. 25, 2006). Moreover, "higher education institutions should measure student learning using quality assessment data ... designed to assess general education outcomes for undergraduates in order to improve the quality of instruction and learning" (U.S. Department of Education, p.24, 2006). The Commission also stated that assessment activities should include "value-added measurements that indicate how students' skills have improved over time ..." (U.S. Department of Education, p.24, 2006). These comments and others in the final report by the Commission have largely been interpreted as a call to create a standardized test to allow the Department of Education the ability to study college performance. Failure to conduct these assessment activities would result in a denial of federal funding to a college or university for student aid or for research. As one may anticipate this assessment oversight has been widely criticized. Thus, reaching a consensus on how to assess each outcome is controversial, particularly in the field of economics. Measuring student achievement of course outcomes is not an easy task, as each outcome must be clearly identified and accurately measured.

This paper describes the methods used to assess student achievement of the stated course outcomes in introductory level economics courses at two different colleges, the Albany College of Pharmacy and Health Sciences (ACPHS) and Siena College, during the 2007 academic year. Specifically, we detail the normal course assessment activities that are used, such as homework and exams. Additionally, a pre-test and post-test assessment exam developed from the course outcomes is described. The following sections of this paper will: (2) explore the literature on the methods of assessing outcomes of student learning and for economics courses, (3) describe the introductory economics courses taught by the authors at the two colleges and the outcomes for these courses, (4) 
explain the traditional assessment techniques used by the authors in the introductory economics courses at the two colleges, (5) describe and analyze the pre-test and post-test exams that are used by the authors in these courses, and lastly (6) conclude and discuss the implications of the techniques described in the paper.

\section{ASSESSMENT LITERATURE}

Whether exploring assessment from a college or university level or from an individual course perspective, a variety of approaches towards assessment exists. For our purposes in this paper we will briefly examine two of the more popular techniques. One method that has received a considerable amount of attention lately is the electronic portfolio. An electronic portfolio is a digital collection of a student's work to document the achievement of specified outcomes. The electronic portfolio is developed with student participation in choosing the contents, the criteria for the selections, the conditions for reviewing worth in the selection, and student self-assessment (Paulson, Paulson, and Meyer, 1991). The electronic portfolio illustrates how and what the student is learning. Through the collection of student work over time, progress can be measured. Since the portfolio is electronic, a variety of information can be collected, such as artwork and writing samples. This method of assessment allows students to demonstrate performance through real-world situations (Meyer, 1992). This information can then be used by all parties; students can use the electronic portfolio to develop resumes and applications for jobs and graduate school; faculty members can use the materials to illustrate student achievement of outcomes in their respective courses, while institutions can use this information to provide evidence of student learning to accreditation agencies.

Other forms of technology are also getting used in the assessment of economics courses. For example, Blecha (2001) found that email and the internet are used by nearly all economics instructors. However, other technologically-based activities, such as the use of iPod's and personal digital assistants (PDA), have not been widely adopted (Becker and Watt, 1996; Becker, 2004) and cause great debate in their use. Some, like James Burke, anticipate that the use of technology will be revolutionary; for instance, the use of handheld computers and personal digital assistants to conduct economics experiments in class (Thomas, 1996, p. 16; Sosin and Goffe, 2006). Others fear technology will provide a disincentive for learning, diminish the role of instructors as a conduit for information, reduce student attention spans, and writing abilities (Stoll, 1995; Sosin and Goffe, 2006). However, the use of technology in economics courses has yielded both positive and negative results. Grimes and Ray (1993) found that computer simulations and tutorials improved student attitudes towards economics and improved student learning. Leuthold (1998) made similar conclusions. Agarwal and Day (1998) furthered the research and found that the Internet assists student learning, student perception of the instructor, and student attitudes towards economics. In a large study of instructors and students in introductory level courses, Sosin et al. (2004) found a statistically significant improvement in student performance in classes that used technology.

However, Sosin et al. did find that instructors using PowerPoint as a replacement for more traditional teaching methods had a negative impact on student performance (grades). Others have also found that technology can have a negative impact on student learning. Terry, Lewer, and Macy (2003) conducted a comparison of three courses; an online course, a mixed course that replaced some classroom time with online time, and a classroom course. They found that, controlling for student ability, effort, and demographic characteristics, students enrolled in the online course performed at a significantly lower rate than classroom students. Students in the mixed course also performed worse than classroom students; however, this was not a significant result. Brown and Liedholm (2002) provided streaming videos of class lectures and used classroom time for active learning exercises. They found that students learned better in a strictly classroom course. However, Brown and Liedholm (2004) built upon this experience and used a mixed course of technology and in-class lectures and activities. They found that students were more positive about the class and their performance. Counter to the findings of Terry et al., Brown and Liedholm suggested that a mixed course is a better option than an online course or a strictly classroom course.

While the use of technology in education is debatable, another approach to assessment that has received a considerable amount of attention is the standardized test. As one may surmise, this method of assessment is highly controversial. Opponents of standardized testing claim that these exams are unfair because of the variability in the outcomes across colleges and universities, that the exams do not reflect differences in student learning, nor do they measure student achievement. Questions such as: "Should everyone be learning the same thing?" and "How do we compare student achievement for those with different ability levels?" have been raised regarding this issue. These 
are but two of the myriad of questions that have been asked. Yet standardized tests are attractive because they are an easy way to collect data on student learning which can then be used for comparative purposes within and across institutions. In fact, the Organization for Economic Cooperation and Development is considering an international test of higher education learning (Inside Higher Ed, 2008). Such a test can be used to examine how much general knowledge a student has retained over his or her academic career or how students can perform in their majors/fields of specialization.

One such example of a standardized test for a field of study is the Test of Understanding of College Economics (TUCE). The TUCE is a standardized test that was first administered in 1975 for assessment purposes (Saunders, 1991). Although the exam has been used for numerous studies, the test is controversial due to its content and that the questions are multiple-choice (Walstad, 2001). The exam has two objectives: (1) to provide a reliable and valid assessment tool for students in introductory economics courses; and (2) to provide baseline data for a national sample of students from introductory classes so instructors can compare the performance of their classes on both the pre-test and post-test to a national average (Walstad, Watts, and Rebeck, 2006). As the chair of the original TUCE committee stated, "The test will emphasize the ability to apply economic principles to real problems, including issues of public policy" (Fels, 1967, p. 664). The latest edition of the exam, TUCE-4, was administered in the fall of 2005, with 3,255 students taking both the thirty question pre-test and post-test in macroeconomics and 2,789 students taking the thirty question pre-test and the post-test in microeconomics (Walstad, Watts, and Rebeck, 2006). For more specifics on the TUCE, readers are encouraged to follow their own curiosity to Walstad, Watts, and Rebeck (2006), Fels (1967), Saunders (1981; 1991a; 1991b), and Saunders, Fels, and Welsh (1981).

The following sections describe the two colleges and courses where the assessments took place and the approach to assessment at each institution.

\section{DESCRIPTION OF THE COLLEGES AND COURSES}

\subsection{Albany College of Pharmacy and Health Sciences}

The Albany College of Pharmacy and Health Sciences is a professional college, preparing students to become pharmacists. The college has been described as a liberal arts college with one major, pharmacy. As such, students are required to take a variety of courses in non-pharmacy related fields, including economics. The Economics of Health Care is a required course for both second-year students and non-traditional accelerated students. Accelerated students have a variety of backgrounds; some with Associate's degrees, most with Bachelor's degrees, and a few with Master's degrees and doctorates. Thus, these students, if they have taken any economics courses at all, have done so many years prior to enrolling in the Economics of Health Care course. In addition to the challenge of teaching a diverse student population, the Economics of Health Care is an upper-level undergraduate course requiring several economics courses as prerequisites. At the Albany College of Pharmacy and Health Sciences the introductory economics course is the Economics of Health Care.

Therefore, students taking this course lack the foundation in economics that is necessary to completely understand the advanced topics that are covered. As such, students must be taught the foundation concepts of economics, as well as the advanced topics of the Economics of Health Care, all while trying to ensure that the concepts are retained for the next economics-based course two years later in the curriculum. In an attempt to accomplish this task, the first half of the class was dedicated to teaching the principles of microeconomics and macroeconomics, and then the second half was devoted to applying those introductory concepts to the advanced health economics material.

As a required course, 302 students were enrolled. To assist in keeping such a large class focused on what they are expected to know by the end of the course, a very detailed set of achievable but challenging learning objectives was developed. Upon completion of the course, students taking the Economics of Health Care at the Albany College of Pharmacy and Health Sciences should be able to: 
1. understand basic economic tools, apply these techniques to issues related to the production and distribution of services, and understand what economists think is different about health care markets as compared to other markets;

2. understand the role of economic incentives, competition (or lack thereof), and regulation on the functioning of the medical care system and should be able to use this information to assess the economic efficiency and equity aspects of the current system;

3. have a broad understanding of institutional changes going on currently in the medical care system and be able to analyze the economic aspects of medical care policy issues and reform proposals using cost evaluation techniques;

4. $\quad$ explain the concept of opportunity cost, and apply this to the health care industry;

5. explain the principle of comparative advantage and how it affects trade, particularly in the pharmaceutical industry;

6. understand how various factors shift supply and demand curves and understand the consequences for equilibrium price and quantity;

7. calculate and discuss elasticity of supply and demand and how they affect business decisions, especially for the pharmaceutical industry;

8. explain and calculate average and marginal cost;

9. $\quad$ contrast perfect and imperfect markets;

10. apply the principles of consumer and producer surplus to explain efficient levels of production and sales in a market, and to use these concepts to measure health outcomes;

11. define and calculate gross domestic product;

12. explain the role of capital investment, education, and technology in determining economic growth;

13. explain what factors determine the level of, and to define unemployment;

14. explain the strategy behind government policies to stabilize the economy and the specific role of the Federal Reserve.

While the number of learning objectives is large, a more comprehensive and detailed listing was thought to be necessary so that students not particularly interested in taking economics in the first place would know exactly what they are expected to learn, at a minimum. For professional students such as those at ACPHS this approach works because of student hypersensitivity to coursework in non-pharmacy classes and towards grades.

\subsection{Siena College}

Siena College is a Catholic and Franciscan undergraduate liberal arts college and its students can choose from 29 degree programs, 46 minors and certificate programs, and professional curricula in Secondary Education, Pre-Medical, Pre-Law, and Social Work offered by three schools: Liberal Arts, Science, and Business. The required college core courses provide Siena students with a broad, challenging, and inspiring education.

The introductory economics courses at the college are the Principles of Economics, Micro and the Principles of Economics, Macro. These courses are optional as college core courses and are required as business core courses for all students majoring in economics, accounting, marketing and management, and finance. Usually, the economics principles courses are taken by students in their first or second year. Course objectives are common for all principles of economics faculty and students are made aware of them at the beginning of the semester. After completion of the course, students taking the Principles of Economics, Micro at Siena College should be able to:

1. Demonstrate understanding of the fundamental microeconomic concepts including demand and supply, elasticity, equilibrium, prices, markets (product and resources), cost of production (supply), and revenue structure.

2. Critically analyze and interpret economic data.

3. Apply economic reasoning to analysis of current events. 
For Principles of Economics, Macro, at the end of the semester, students should be able to:

1. Demonstrate understanding of the fundamental macroeconomic concepts including unemployment, inflation, economic growth, aggregate demand and aggregate supply, macro equilibrium, national income accounting, monetary policy, fiscal policy, public debt, and alternate paradigms.

2. Critically analyze and interpret economic data.

3. Apply economic reasoning to analysis of current events.

In the fall of 2007, sixty-nine students were enrolled in the two sections of macroeconomics assessed and in the spring of 2008 thirty-six students took the microeconomics course. These small class sizes enabled the use of a variety of teaching and assessment techniques described in more detail in the following section.

\section{APPROACHES TO ASSESSMENT}

\subsection{Economics of Health Care}

The Economics of Health Care was taught using a mix of traditional classroom teaching methods and technology. Classroom time consisted of lectures and activities, such as viewing documentaries related to the material being taught. Technology was used for summative assessment activities that consisted of homework, a research project, and exams. Due to the size of the class and the classroom, other techniques were considered but found to not be feasible. The exams and homework assignments used technology, described below, both within the classroom and outside to provide multiple indicators of student achievement, using a combination of fixed and constructive response items. Constructive response requires students answer questions by writing, calculating, graphing, or some other activity (e.g. short answer, numerical or word problems). For example, students were shown documentaries on the economics of the pharmaceutical industry and required to post a written paragraph in a discussion board in the course's Blackboard website. Fixed response questions require that students select the best answer from a fixed set of answers, such as multiple choice and true/false (Walstad, 2001). Additionally, a variety of in-class and out-of-class projects, group-work, and assignments was used. Such an approach is important because it provides students frequent opportunities for self-assessment (Crooks, 1998; Walstad, 2001).

Homework assignments typically consisted of thirty-five to forty questions twice per week, with questions ranging from news analyses to multiple-choice to calculation and graphing. These assignments were done out-ofclass in an interactive format using Aplia.com, a fee-based economics education company. In 2007, students were assigned 880 homework questions. Such a large amount of homework may seem to be excessive; however, this approach was used to promote learning of the material. In pharmaceutical education students are required to memorize a substantial amount of material, a common practice in medical-related fields. Therefore, to counteract rote learning, homework was assigned every class to encourage student understanding and the retention of the material. The use of Aplia for homework enabled several additional levels of assessment to be implemented. For every problem assigned aggregate class responses and performance could be viewed so that the material students had trouble comprehending could be revisited in the next class period. In addition to the aggregate class responses and performance, individual student achievement could be tracked so that those students lagging in understanding could be contacted so their problems could be addressed either by individual meetings with the instructor, tutoring sessions, or a combination of the two. Furthermore, students receive an explanation of the correct answer on questions they answered incorrectly, thus receiving immediate feedback on their homework and providing a level of self-assessment by the student.

Group learning was encouraged for all coursework, as students, particularly those that are competitive for grades, often learn from one another in such an environment. This holistic approach to education enables pharmacy students, as well as others, the ability to build their knowledge through inquiry, a major component of their education. Using in-class and out-of-class projects, group-work, and assignments is important because it provides students frequent opportunities for self-assessment (Crooks, 1998; Walstad, 2001). For example, students received instant feedback on their homework assignments and an explanation of how to correctly answer a question if they answered incorrectly. 
In addition to the homework, two exams were given. Both exams were done online. The first exam was a take-home exam consisting of sixty-seven questions. Take-home exams are effective instruments to encourage learning the material rather than memorization. Similar to homework assignments, those students that are competitive for grades will look in their textbook, notes, and other course materials to find the answers to the exam questions, thus learning at the same time. The second exam was in-class and closed book. Students had two hours to answer fifty-six questions of a various types: calculation, graphing, multiple-choice, and fill-in.

The course research project required students to merge the information that was taught on the introductory level and the material that was taught on health economics to analyze the impacts of economic growth and energy consumption on the public health of a country. Students were assigned to a group and each group was assigned a country to research. The groups were required to develop a research plan to illustrate the interactions between economic growth, energy consumption, and public health. To accomplish this task the students had to develop a hypothesis, examine the literature on the topic, collect data to test their hypothesis, and then analyze their results. Once their research was finished, each group created a poster to present their findings at a seminar open to the entire college community. At this seminar, each group was interviewed about their assigned country and their results. Thus, the research project created a situation where students had the opportunity to illustrate in a very concrete fashion that they could connect all the course material.

As stated previously, pharmacy students undertake a considerable amount of rote learning, so the techniques described above were used to neutralize that learning approach and to encourage learning and retention.

\subsection{Principles of Economics, Micro and Macro}

Both courses, Principles of Economics, Micro and Macro, were taught using a combination of interactive teaching, a couple of PowerPoint presentations, and group work. Students' progress was continuously assessed during the semester through homework, reading quizzes, group work, and midterm and final exams. Reading quizzes had the purpose of evaluating students' ability to read, comprehend, and summarize basic and more technical information (such as Wall Street Journal articles for both micro and macro or selections from The Secrets of Economic Indicators for macro). The skills developed during the semester were tested in the midterm and final exams with essay questions and they addressed the third course objective, the analysis of current events. Class group work was used to teach students to solve problems and it addressed the second course objective, that of critically analyzing and interpreting economic data. The achievement of these skills was evaluated along with the first course objective, the understanding of fundamental concepts, using multiple-choice questions for homework and as part of the midterm and final exams.

For the Principles of Economics, Micro course, the homework consisted of twenty to thirty multiple-choice questions assigned once a week and it was intended to encourage an intense use of the textbook. The microeconomics midterm exam was take-home; students had one hour and forty minutes to answer fifty multiplechoice questions using any means they considered necessary. Students feed-back invariably stated that the exam was difficult even though it was take-home and they had the freedom to use any help. The signal sent to my students was that an exam in not necessarily easy if they can use all the materials they want; the time limit differentiated the students who studied and those who did not. The final exam was a combination of sixty-one multiple-choice questions and two essay questions to be answered in two hours. The multiple-choice questions tested students' correct understanding of the microeconomic concepts studied, and their ability to solve problems involving graphs. The essay questions evaluated students' ability to analyze portions of a newspaper article on current events and interpret it using the supply and demand graphical analysis.

For the Principles of Economics, Macro course, the weekly homework was a combination of ten to fifteen multiple-choice questions and Wall Street Journal and The Secrets of Economic Indicators reading assignments. The dual focus of the course was first on the achievement of a correct understanding of the macroeconomic concepts and second on current events analysis and the understanding of macroeconomic policies. The first exam, administered in class with no additional materials, took one hour and was a combination of thirty multiple-choice questions assessing course objectives one and two, and four essay questions assessing the third course objective. The second exam was take-home with a predetermined duration of one hour and the option of using any supporting materials. It 
consisted of thirty seven multiple-choice questions assessing course objectives one and two. Students' opinion about the difficulty of the take-home exam echoed that of their peers in the microeconomics course. The final exam was similar to the first exam and asked thirty eight multiple-choice questions and two essay questions. In addition, the final exam had a take-home part asking students to write a two pages essay to show the evolution of US monetary policy based on the information provided by four Wall Street Journal articles.

\section{OUTCOMES BASED PRE-TEST AND POST-TEST}

As illustrated by the description of the student body and the introductory economic courses, there are vast differences between the two colleges. Additionally, the teaching methods used by the authors are very different. We recognize that these distinctions could affect the analysis outcomes. However, the stated outcomes of the courses are very similar and there is no effective statistical analysis for accounting for these differences. Therefore, we wanted to explore if there are any differences in the student achievement of the outcomes in the courses at the two colleges, so we developed and used an identical pre-test and post-test. Such an approach is typical for economists and allows for various teaching methods to be examined for their effectiveness (Sosin, et al., 2004; Hannah, 1996; Manning, 1996; Agarwal and Day, 1998). The pre-test and post-test assessment exams have been criticized for their data loss and selection bias due to missed tests or students dropping the course (Becker and Walstad, 1990; Becker, 1997). However, as Becker (2001) has concluded, researchers have no alternative but to use the readily available tests, such as the TUCE, or to create an alternative assessment device.

Instead of using the TUCE, which is widely used and has the benefit of a national benchmark but has been criticized for not testing higher-level cognitive abilities and for being out-of-date (Sosin, et al, 2004), an assessment exam was created that specifically targets the course objectives for the three courses. This was achieved because the assessment for the Economics of Health Care course focused on the introductory microeconomic and macroeconomic concepts that are taught in the Principles of Economics, Micro and Principles of Economics, Macro courses.

An assessment exam of ten questions was developed for the introductory macroeconomics content and an assessment exam of twenty questions was created for the concepts taught in introductory microeconomics. The content of the macroeconomic assessment exam included measuring economic performance (i.e. GDP and its components, real values, nominal values, inflation, unemployment, and productivity) and financial markets. The microeconomics assessment exam included questions about markets and price determination (i.e. supply and demand, elasticity, and monopoly), theory of the firm (i.e. profit, revenues, costs, and marginal analysis), factor markets (i.e. consumer and producer surplus), and the economic problem (i.e. normal goods, opportunity cost).

The pre-tests and post-tests in microeconomics and macroeconomics were administered to the entire enrollment of the courses at both colleges; however, only 297 students in the Economics of Health Care course, 32 in Introductory Microeconomics, and 56 in the Introductory Macroeconomics course completed both parts of the assessment exam. Not surprisingly, the pre-test results indicate that students in the courses at both colleges have limited knowledge of economics.

The summary statistic results are presented in Table 1 . The observed differences, provided in Table 2, for the Economics of Health Care students range from -30 to +80 on the macroeconomics exam and -35 to +90 on the microeconomics exam. The mean and median differences in the assessment scores for the microeconomics exam are 22.2 and 20, and 26.3 and 30 for the macroeconomics exam. The observed differences, also in Table 2, for the courses at Siena College range from -40 to +60 on the macroeconomics exam and -10 to +70 on the microeconomics exam. The mean and median differences in the assessment scores in the courses at Siena College are 25.2 and 22.5 for the microeconomics exam and 20.2 and 20 for the macroeconomics exam. 
Table 1. Summary Statistics

\begin{tabular}{lcccc} 
& \multicolumn{2}{c}{ SIENA COLLEGE } & ACPHS \\
\hline & \multicolumn{2}{c}{ Macroeconomics } & \multicolumn{2}{c}{ Macroeconomics } \\
Mean & Pre-test & Post-test & Pre-test & Post-test \\
Standard Deviation & 40.53 & 60.71 & 43.87 & 70.2 \\
Minimum & 17.2 & 17.77 & 14.64 & 17.8 \\
Maximum & 0 & 10 & 0 & 20 \\
& 90 & 90 & 90 & 100 \\
Mean & \multicolumn{2}{c}{ Microeconomics } & Microeconomics & Post-test \\
Standard Deviation & Pre-test & Post-test & 45.52 & 67.67 \\
Minimum & 34.38 & 59.53 & 12.05 & 17.84 \\
Maximum & 14.07 & 12.6 & 0 & 20 \\
& 0 & 35 & 85 & 100 \\
\hline
\end{tabular}

Table 2. Observed Differences

SIENA COLLEGE

\begin{tabular}{lcc}
\hline & Macroeconomics & Macroeconomics \\
Mean & 20.18 & 26.33 \\
Median & 20 & 30 \\
Standard Deviation & 20.23 & 21.58 \\
Minimum & -40 & -30 \\
Maximum & 60 & 80 \\
& Microeconomics & Microeconomics \\
Mean & 25.16 & 22.16 \\
Median & 22.5 & 20 \\
Standard Deviation & 16.78 & 20.38 \\
Minimum & -10 & -35 \\
Maximum & 60 & 90 \\
\hline
\end{tabular}

Students at the Albany College of Pharmacy and Health Sciences did slightly better on both the pre-tests and the post-tests. While this may seem surprising, the result should not be a complete shock because the majority of students in the Principles of Economics, Micro and the Principles of Economics, Macro at Siena College are firstyear students, whereas the students in the Economics of Health Care at the Albany College of Pharmacy and Health Sciences are second-year and non-traditional students that have had the benefit of having had previous educational experiences and adapting to college-life. Although the overall scores of ACPHS students were better on the pre-test and post-test, Siena College students had a greater improvement $(25.16 \%$ compared to $22.15 \%)$ on the microeconomics assessment. However, ACPHS students had a greater improvement (26.33\% compared to 20.2\%) on the macroeconomics assessment. These results are interesting because students in the Principles of Economics, Macro course, received a full semester of instruction, whereas students in the Economics of Health Care received approximately four weeks of macroeconomic coursework. Furthermore, the Economics of Health Care course material is taught at both the introductory and the intermediate/advanced level, in comparison to the Principles of Economics, Micro course, which is taught solely at the introductory level. For these reasons the authors anticipated that these results would be the opposite of what occurred.

Additional statistical analysis was conducted to determine if the pre-test scores are statistically significant at the $95 \%$ confidence level from the post-test scores or not for each course. The results, with p-values of 0.00 , indicate that the students in each course did have a statistically significant improvement. In addition to confirming that the post-test scores were statistically significant from the pre-test results, an ANOVA was conducted to determine if the differences between the courses at the two colleges had an effect on the assessment exam results. Pre-test scores were tested to examine if there are differences in the students at ACPHS and Siena College. The results of the ANOVA showed that there are no statistically significant differences. Post-test scores were also tested 
to determine if the different teaching methods had an effect on student achievement of course objectives; there was no statistically significant difference.

\section{CONCLUSIONS AND DISCUSSION}

The Principles of Economics courses at Siena College are taught to students typically majoring in a business degree program in a traditional four-year format. The Economics of Health Care, typically an upper-level undergraduate course, is the introductory economics class at the Albany College of Pharmacy and Health Sciences and is taught to second year students as well as non-traditional students. This paper explored the assessment activities for these courses. Typically, assessment has comprised of a combination of homework, quizzes, exams, term papers, and class participation. However, with the emphasis on assessment by accreditation bodies assessment techniques have expanded to include pre-tests and post-tests. In this paper we describe a pre-test and post-test that was developed and used to measure student achievement of the stated outcomes in the courses. We argued that an assessment exam designed using course objectives is better than a standardized test such as the TUCE which tests specific categories of economic thought.

The results of the exams indicate that students did have a significant improvement in their understanding of the course material for both microeconomics and macroeconomics at both institutions. Students at the Albany College of Pharmacy and Health Sciences performed better on the pre-test portions of the assessment exam; likely due to the fact that these students are second-year and non-traditional students. However, the post-test results were mixed. Siena College students enrolled in the Principles of Economics, Micro course improved, on average, five points more than Albany College of Pharmacy and Health Sciences students on the microeconomics assessment exam. ACPHS students improved, on average, by four more points on the macroeconomics assessment exam than students taking the Principles of Economics, Macro course at Siena College. We expected these results to be reversed and are unsure as to why the results occurred as they did. While these results reaffirm the findings from the t-tests we understand that these tests will not be able to completely isolate the differences between the classes and, as such, the results need to be viewed with some caution. However, even with the word of caution the results indicate that assessment created specifically to measure the achievement of course outcomes is an appropriate assessment tool.

The results, however, do indicate that an assessment exam developed using the stated outcomes of the course is an appropriate method of assessment and could be better than a standardized exam. As we have shown in a cross-college example, the pre-test and post-test exams provided meaningful information on student retention. Assessment exams developed in this manner enable colleges/universities and academic departments to create assessment activities in a manner that eliminates the problems associated with standardized tests. Therefore, the assessment exam and the results described in this paper are important because a pre-test and post-test created using course outcomes and objectives bridges the differences of student capabilities and teaching methods that a standardized exam will not be able to accomplish.

\section{AUTHOR INFORMATION}

John M. Polimeni is Assistant Professor of Economics at the Albany College of Pharmacy and Health Sciences. He earned a Ph.D. in Ecological Economics from Rensselaer Polytechnic Institute, M.A. in Economics and a Certificate in Graduate Studies on Regulatory Economics from S.U.N.Y. at Albany, and a B.S. in Mathematics from Rensselaer Polytechnic Institute. His research interests include ecological economics, sustainable development, and economic development; he has published a number of papers in this area. Additionally, he has published several papers on Jevons' Paradox and energy consumption, and a book on the topic entitled Jevons' Paradox and the Myth of Resource Efficiency Improvements.

Raluca I. Iorgulescu is Assistant Professor of Economics at Siena College in New York State, USA and a researcher at the Romanian Institute for Economic Forecasting. She received her B.S. in Physics from Bucharest University, Romania and her Ph.D. in Ecological Economics from the School of Humanities and Social Sciences at Rensselaer Polytechnic Institute, USA. Iorgulescu has published several papers on economics education, Jevons' Paradox and energy use, on community supported agriculture, on macroeconomic topics, and on Nigeria. Her 
research interests are in the fields of ecological economics, economic and sustainable development, and transitional economies; these areas of interest are linked together by examining the relationship between sustainable development and local community involvement using the Multi-Scale Integrated Analysis of Societal Metabolism (MSIASM) approach.

\section{REFERENCES}

1. Agarwal, R. and A.E. Day. (1998). "The Impact of the Internet on Economic Education,” Journal of Economic Education, 29(2): 99-110.

2. $\quad$ Angelo, T.A. and K.P. Cross. (1993). Classroom Assessment Techniques: A handbook for College Teachers, $2^{\text {nd }}$ edition, San Francisco: Jossey-Bass.

3. Association of American Colleges and Universities. (2002). "Greater Expectations: A New Vision for Learning as a Nation Goes to College," National Panel Report, Washington, D.C.

4. Baumohl, B. (2007). The Secrets of Economic Indicators: Hidden Clues to Future Economic Trends and Investment Opportunities, $2^{\text {nd }}$ edition, Philadelphia: Wharton School Publishing.

5. Becker, W.E. (1997). “Teaching Economics to Undergraduates,” Journal of Economic Literature, 35(3): 1347-1373.

6. _ . (2001). "What Does the Quantitative Research Literature Really Show About Teaching Methods?," Unpublished Manuscript Presented at the Scholarship of Teaching and Learning Colloquium, Indiana University, Blooming, March 2.

7. _. (2004). "Quantitative Research on Teaching Methods in Tertiary Education," In: W.E. Becker and M. Andrews, (eds.), The Scholarship of Teaching and Learning in Higher Education, Bloomington: Indiana University Press.

8. Becker, W.E. and W.B. Walstad. (1990). "Data Loss from Pretest to Posttest as a Sample Selection Problem," Review of Economics and Statistics, 72(1); 184-188.

9. Becker, W.E. and M. Watts. (1996). "Chalk and Talk: A National Survey on Teaching Undergraduate Economics," American Economic Review, 86(May): 448-453.

10. Blecha, B. (2001). "Learning By Doing and the Choice of Instructional Technology," Presentation at the Midwest Economics Association Meetings, Cleveland, March.

11. Bloom, B.S. (1956). Taxonomy of Educational Objectives. New York: David McKay.

12. Brown, B.W. and C.E. Liedholm. (2002). "Can Web Courses Replace the Classroom in Principles of Microeconomics?," American Economic Review, 92(May): 444-448.

13. _ (2004). "Designing Online Course Materials Based on Student Preferences in Using Learning Resources," Presentation at the Allied Social Science Association, San Diego, January.

14. Fels, R. (1967). "A New Test of Understanding in College Economics," American Economic Review, Papers and Proceedings, 57(2): 660-666.

15. Grimes, P.W. and M.A. Ray. (1993). "Economics: Microcomputers in the College Classroom - A Review of the Academic Literature," Social Science Computer Review, 11(Winter): 452-463.

16. Hannah, R. (1996). "Internet Sources for Business Educators," Journal of Education for Business, 71(4): 209-213.

17. Leuthold, J. (1998). "Building a Homepage for Your Economics Class," Journal of Economic Education, 29(Summer): 247-261.

18. Manning, L. (1996). "Economics on the Internet: Electronic Mail in the Classroom," Journal of Economic Education, 27(3): 201-204.

19. Meyer, C. A. (1992). What's the difference between "authentic" and "performance" assessment? "Educational Leadership," 49(8), 39-40.

20. Paulson, L. F., Paulson P. R., \& Meyer C. (1991). What makes a portfolio a portfolio? "Educational Leadership," 48(5), 60-63.

21. Saunders, P. (1981). Revised Test of Understanding in College Economics: Interpretive Manual, New York: National Council on Economic Education.

22. _. (1991a). Test of Understanding of College Economics: Examiner's Manual, Third Edition, New York: National Council on Economic Education.

23. _. (1991b). "The Third Edition of the Test of Understanding of College Economics," American Economic Review, Papers and Proceedings, 81(2): 32-37. 
24. Saunders, P., R. Fels, and A.L. Welsh. (1981). "The Revised Test of Understanding of College Economics," American Economic Review, Papers and Proceedings, 71(2): 190-194.

25. Sosin, K. and W.L. Goffe. (2006). "Using the Internet and Computer Technology to Teach Economics," In: W.E. Becker, M. Watts and S.R. Becker, (eds.), Teaching Economics: More Alternatives to Chalk and Talk, Cheltenham: Edward Elgar.

26. Sosin, K., B.J. Blecha, R. Agarwal, R.L. Bartlett, and J.I. Daniel. (2004). "Efficiency in the Use of Technology in Economic Education: Some Preliminary Results," American Economic Review, 94(May): 253-258.

27. Stoll, C. (1995). Silicon Snake Oil: Second Thoughts on the Information Highway, New York: Doubleday.

28. Terry, N., J. Lewer, and A. Macy. (2003). "The Efficacy of Alternative Instruction Modes in Economics," Journal of Economics and Economic Education Review, 4(1): 23-34.

29. Thomas, D. (1996). "Speaker Touts Reach of Web," Omaha World Herald, October 26: 61.

30. U.S. Department of Education. (2006). "A Test of Leadership: Charting the Future of U.S. Higher Education," http://www.ed.gov/about/bdscomm/list/hiedfuture/index.html

31. Walstad, W.B (2001). "Improving Assessment in University Economics," Journal of Economic Education, Summer: 281-294.

32. Walstad, W.B., M. Watts, and K. Rebeck. (2006). “Assessing Student Achievement in Economics with the Test of Understanding of College Economics (TUCE)," Paper Presented at the National Council of Economic Education and National Association of Economic Educators Annual Meeting, New York City, New York, October 12. 
NOTES 